\title{
Antitumor effects of pristimerin on human osteosarcoma cells in vitro and in vivo
}

This article was published in the following Dove Press journal:

OncoTargets and Therapy

\author{
Yuki Mori' \\ Toshiharu Shirai' \\ Ryu Terauchi' \\ Shinji Tsuchida' \\ Naoki Mizoshiri' \\ Daichi Hayashi' \\ Yuji Arai² \\ Tunao Kishida ${ }^{3}$ \\ Osam Mazda ${ }^{3}$ \\ Toshikazu Kubo' \\ 'Department of Orthopaedics, \\ ${ }^{2}$ Department of Sports and Para- \\ Sports Medicine, ${ }^{3}$ Department of \\ Immunology, Graduate School of \\ Medical Science, Kyoto Prefectural \\ University of Medicine, Kyoto, Japan
}

Correspondence: Toshiharu Shirai Department of Orthopaedics, Graduate School of Medical Science, Kyoto Prefectural University of Medicine, Kawaramachi-Hirokoji, Kamigyo-ku, Kyoto 602-8566, Japan

Tel +81752515549

Fax +8I 75 25I 584I

Email shirai.t77@gmail.com

\begin{abstract}
There are very few treatments for musculoskeletal tumors, compared to other cancers; thus, novel therapeutic drugs are needed. Pristimerin (PM) is a triterpene compound isolated from plant extracts that reportedly has antitumor effects on various cancers, such as of the breast and prostate. The purpose of this study was to evaluate the antitumor effects of PM on human osteosarcoma cells. Treatment of the human osteosarcoma cell lines, MNNG and 143B, with PM led to a dose-dependent decrease in cell viability. The effects of PM on apoptosis were evaluated with the Annexin V/propidium iodide assay and analysis of caspases 3, 8, and 9 activities. Western blot analysis showed that PM caused a decrease in the expression of Akt, mTOR, and $\mathrm{NF}-\kappa \mathrm{B}$. The volumes and weights of human osteosarcoma xenografts decreased significantly with PM treatment. The results of this study revealed that PM can inhibit human osteosarcoma growth in vitro and in vivo, and may be a novel therapeutic agent for the disease.
\end{abstract}

Keywords: pristimerin, osteosarcoma, apoptosis, caspase, Akt

\section{Introduction}

Osteosarcoma is the most common primary malignant bone tumor, accounting for approximately $20 \%$ of all malignant bone tumors. ${ }^{1}$ Although surgery was the only treatment until the 1970 s, the survival rate dramatically improved with the introduction of chemotherapy in the $1980 \mathrm{~s}^{2}$ However, there have been no significant advances in osteosarcoma treatment for osteosarcoma for almost 40 years, despite extensive research. ${ }^{3,4}$ Although the development of several novel molecular targeted drugs for the treatment of soft-tissue sarcomas is well advanced and molecular targeted drugs, novel therapeutic drugs, have been developed for soft-tissue sarcomas, molecular targeted drugs for osteosarcoma are still in the preclinical or early clinical trial phase., ${ }^{5,6}$

In recent years, natural anticancer drugs have received much attention, including Yondelis (trabectedin), a natural compound from the tunicate, Ecteinascidia turbinata, which has been used to treat soft-tissue sarcoma. ${ }^{7,8}$ Terpenoids are a large and diverse class of natural compounds that occur widely in nature as a secondary metabolite of organisms, and are derived biosynthetically from units of isoprene. Among the terpenoids, triterpenes reportedly possess anti-inflammatory, antipyretic, and antitumor effects. ${ }^{9,10}$ Pristimerin (PM) is a quinoid-type triterpene isolated from members of the Celastraceae and Hippocrateaceae plant families that was recently shown to have antitumor effects against glioma, cervical cancer, and prostate cancer. ${ }^{11-13}$ In addition, PM induces cell death via various mechanisms such as caspase activation, changes in mitochondrial membrane potential, and inhibition of anti-apoptotic factors, including nuclear factor kappa-light-chain-enhancer of activated B cells (NF- $\mathrm{BB})$ and Akt. ${ }^{12,14}$ Furthermore, some studies have shown that PM can inhibit tumor 
angiogenesis and the development of drug resistance..$^{15,16}$ However, the effects of PM on osteosarcoma cells have not been reported.

The purpose of this study was to evaluate the antitumor effects of PM in osteosarcoma cells and its mechanism of action, both in vitro and in vivo.

\section{Materials and methods}

\section{Cell lines and culture conditions}

The human osteosarcoma cells MNNG (CRL1547) and 143B (CRL1427) were obtained from the American Type Culture Collection (Rockville, MD, USA). The Normal Human Osteoblast (NHOst) cell line was obtained from Lonza Biosciences (Walkersville, MD, USA). All cell lines were cultured in Dulbecco's Modified Eagle's Medium (DMEM; Nacalai Tesque, Kyoto, Japan) supplemented with 10\% fetal bovine serum (FBS; Equitech-Bio, Kerrville, TX, USA), 100 units $/ \mathrm{mL}$ penicillin, and $100 \mathrm{mg} / \mathrm{mL}$ streptomycin (complete DMEM; Nacalai Tesque) at $37^{\circ} \mathrm{C}$ in $5 \% \mathrm{CO}_{2} / 95 \%$ humidified air. Cells were trypsinized with trypsin/ethylenediaminetetraacetic acid (Nacalai Tesque) and subcultured.

\section{Reagents}

PM was purchased from Sigma (St Louis, MO, USA), dissolved in dimethyl sulfoxide (Nacalai Tesque) to yield a $10 \mathrm{mM}$ stock solution, and stored at $-20^{\circ} \mathrm{C}$. PM was diluted to the required concentrations in cell culture medium.

\section{Antibodies}

Anti-phospho-Akt (Ser473), anti-Akt (C67E7), anti-Bax, anti-phospho-mTOR (Ser2448), anti-mTOR (7C10), antiphospho-4E-BP1, anti-NF- $\kappa \mathrm{B}$ p65, anti-phospho-NF- $\mathrm{\kappa B}$ p65 (Ser536), and anti-Cox 2 antibodies were purchased from Cell Signaling Technology (Danvers, MA, USA). Anti- $\beta$ actin, anti-mouse IgG, and anti-rabbit IgG were purchased from Sigma.

\section{Measurement of cell viability}

Cell viability was determined using the RealTime-Glo MT Cell Viability Assay Kit (Promega; Madison, WI, USA). Cells were plated in a Poly-L-Lysine (PLL)-coated 96-well plate at a density of $1 \times 10^{3}$ cells per well in $100 \mu \mathrm{L}$ medium containing $10 \%$ FBS. After $24 \mathrm{~h}$, MT cell viability substrate and Nanoluc ${ }^{\circledR}$ Enzyme were added to the medium, and the cells were exposed to various concentrations of PM. The CentroXS3 LB 960 System (Berthold Technologies; Oak Ridge, TN, USA) was used to measure light emission.

\section{Measurement of caspase activity}

The activity of caspases $3 / 7,8$, and 9 was assessed using the Caspase-Glo 3/7, 8, and 9 Assay (Promega). Experiments were conducted according to Ma et al. ${ }^{17}$ Caspase 3 activity was measured $12 \mathrm{~h}$ after PM treatment. Caspases 8 and 9 most likely act upstream of caspase 3 ; therefore, their activity was measured $8 \mathrm{~h}$ after PM treatment. Caspase activity was measured in luminescence units.

\section{Annexin-V/propidium iodide assay}

Cells were harvested following treatment with PM for $24 \mathrm{~h}$, and stained with $5 \mu \mathrm{L}$ Annexin V-FITC and $5 \mu \mathrm{L}$ PI solution (Nacalai Tesque) for $15 \mathrm{~min}$ at room temperature in the dark. Following incubation, binding buffer was added and the cells were analyzed by flow cytometry using a FACS Vantage Flow Cytometer (Becton Dickinson, Franklin Lakes, NJ, USA). For each sample, 10,000 events were recorded.

\section{Western blotting}

These procedures were conducted as described previously. ${ }^{18}$

\section{Human osteosarcoma xenograft mouse model}

Animal experiments were conducted with approval from the Experimental Animals Committee, Kyoto Prefectural University of Medicine (Code No M29-137).

BALB/C-nu/nu mice (age 5 weeks, females) were purchased from Shimizu Laboratory Supplies (Kyoto, Japan). All procedures were undertaken in accordance with the NIH Guide for the Care and Use of Laboratory Animals. Cells $\left(5.0 \times 10^{6}\right)$ re-suspended in $100 \mu \mathrm{L}$ phosphate-buffered saline were injected into the hypodermis of the back of each mouse. After tumors grew to approximately $100 \mathrm{~mm}^{3}$, the mice were injected intraperitoneally (ip,) with PM at a dose of $1 \mathrm{mg} / \mathrm{kg}$, every other day for 14 days. Untreated mice were used as controls. Tumor size was measured with a caliper (calculated volume $=$ shortest diameter ${ }^{2} \times$ longest diameter $\left./ 2\right)$ at 2-day intervals. All mice were sacrificed, and the tumors were weighed on Day 14. Liver toxicity was checked by blood sample liver enzyme assay on Day 14.

\section{Statistical analysis}

All duplicate and triplicated experiments yielded almost identical results. All experimental data are expressed as means \pm SD. Parametric one-way analysis of variance (ANOVA) was used to test for any differences among the groups. If the result was significant, the Tukey-Kramer test was used to determine specific differences between 
the groups. In all analyses, $p<0.05$ was defined as statistically significant.

\section{Results}

\section{PM inhibits the viability of osteosarcoma cells}

To investigate the effects of PM, a cell viability assay was conducted in osteosarcoma cell lines (MNNG and 143B). The cell lines were treated with various concentrations of $\mathrm{PM}(0.25,0.5,1.0 \mu \mathrm{M})$ for 24,48 , and $72 \mathrm{~h}$. As shown in Figure 1A, PM inhibited the growth of osteosarcoma cells in a dose- and time-dependent manner. The $\mathrm{IC}_{50}$ values of PM in MNNG were $0.80 \pm 0.02,0.39 \pm 0.02$, and $0.32 \pm 0.01 \mu \mathrm{M}$ at 24,48 , and $72 \mathrm{~h}$, respectively. For $143 \mathrm{~B}$, the values were $0.54 \pm 0.04,0.31 \pm 0.002$, and $0.29 \pm 0.004 \mu \mathrm{M}$, respectively (Figure 1B). Thus, 143B cells were more sensitive to PM than MNNG cells. The normal human osteoblast cell line, NHOst, was assessed for comparison with osteosarcoma cells. At a PM concentration of $1 \mu \mathrm{M}$, viability decreased; however, the decrease in viability at 0.25 and $0.5 \mu \mathrm{M}$ was slight compared with the osteosarcoma cell lines.

\section{PM induces apoptosis in osteosarcoma cells}

Next, we used the Annexin V-FITC/PI binding assay to determine whether PM could induce apoptosis in osteosarcoma cells. MNNG and 143B cells were treated with PM $(0-1 \mu \mathrm{M})$ for $24 \mathrm{~h}$, and the binding of Annexin V-FITC was determined by flow cytometry (Figure 2A). The percentage of apoptotic cells (AnnexinV+/PI-) in both cell lines increased in a dosedependent manner (Figure 2B). These results demonstrate the proapoptotic effects of PM in osteosarcoma cells.

\section{PM increased the activities of caspases $3 / 7,8$, and 9 in osteosarcoma cells}

The Caspase-Glo Assay was used to assess the effects of PM on the activities of the main caspases (caspases 3/7 [effectors], 8 , and 9 [initiators]) in osteosarcoma cells. Caspase 3/7 activity was measured $12 \mathrm{~h}$ after PM treatment, whereas caspase 8 and 9 activities were measured 8 h post treatment. As shown in Figure 3A-C, the activities of caspases 3, 8 and 9 increased significantly after treatment with PM. These results demonstrate that apoptosis induced by PM in osteosarcoma cells may involve both intrinsic and extrinsic pathways.
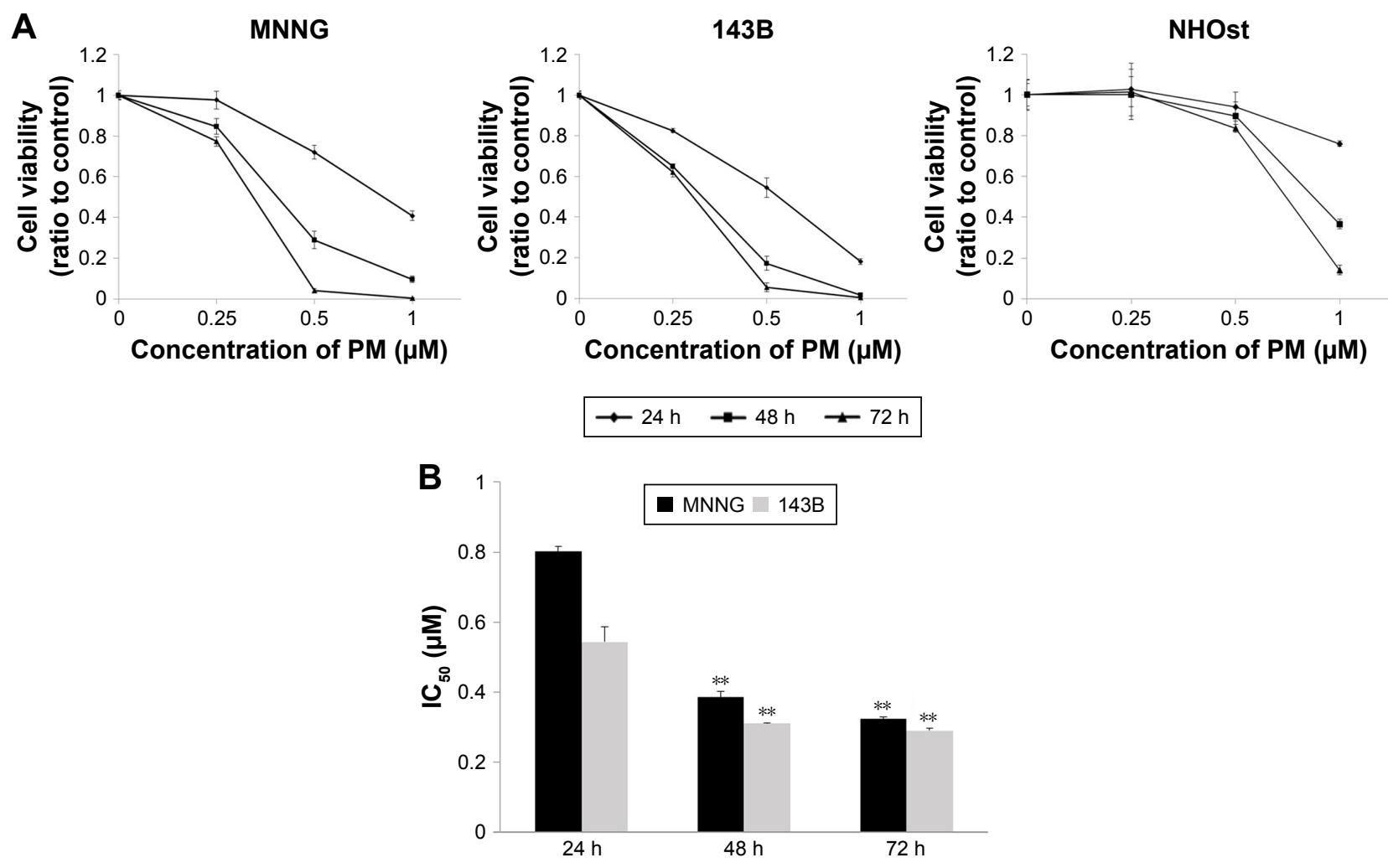

Figure I Effects of PM on osteosarcoma cell viability.

Notes: (A) MNNG, I43B, and NHOst cells were treated with various doses (0-I $\mu \mathrm{M}$ ) of PM for 24, 48, or $72 \mathrm{~h}$, and cell viability was assessed using the RealTime-Glo MT Cell Viability Assay. (B) $I C_{50}$ values were determined after PM exposure for 24,48 , or $72 \mathrm{~h}$. Data are expressed as the mean $\pm S D(n=4)$. ${ }^{* *} p<0.0 I$ vs $I C_{50}$ at $24 \mathrm{~h}$ in each cell. 

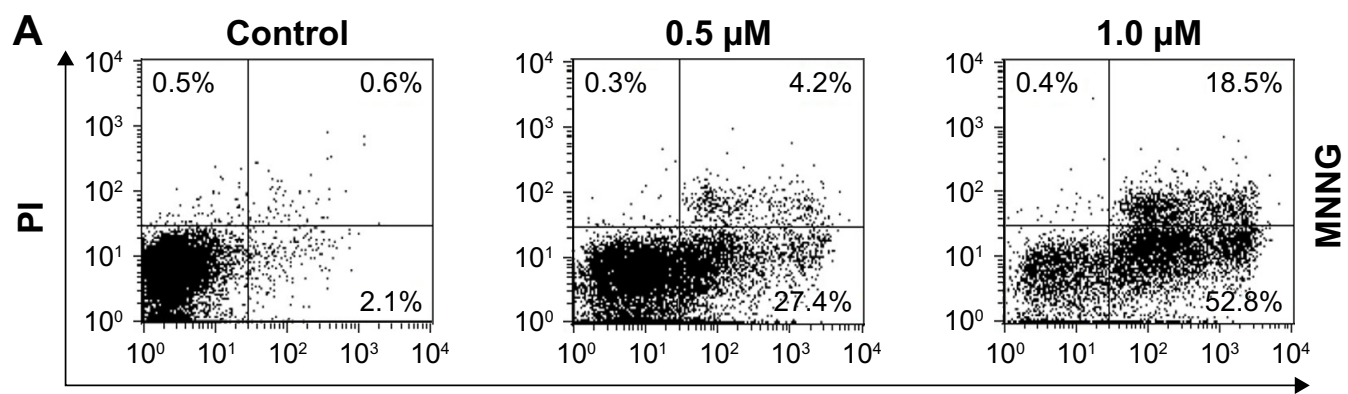

Annexin V-FITC
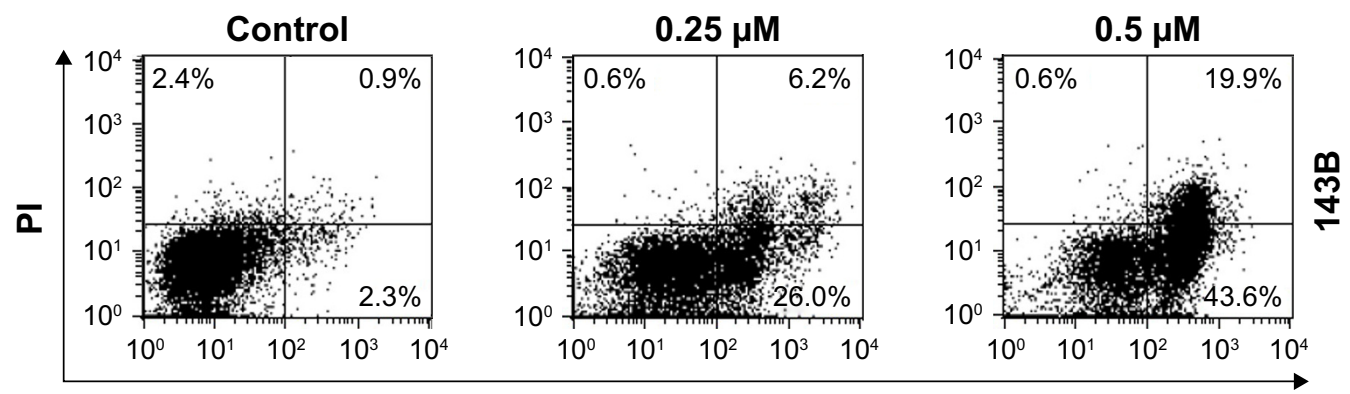

Annexin V-FITC
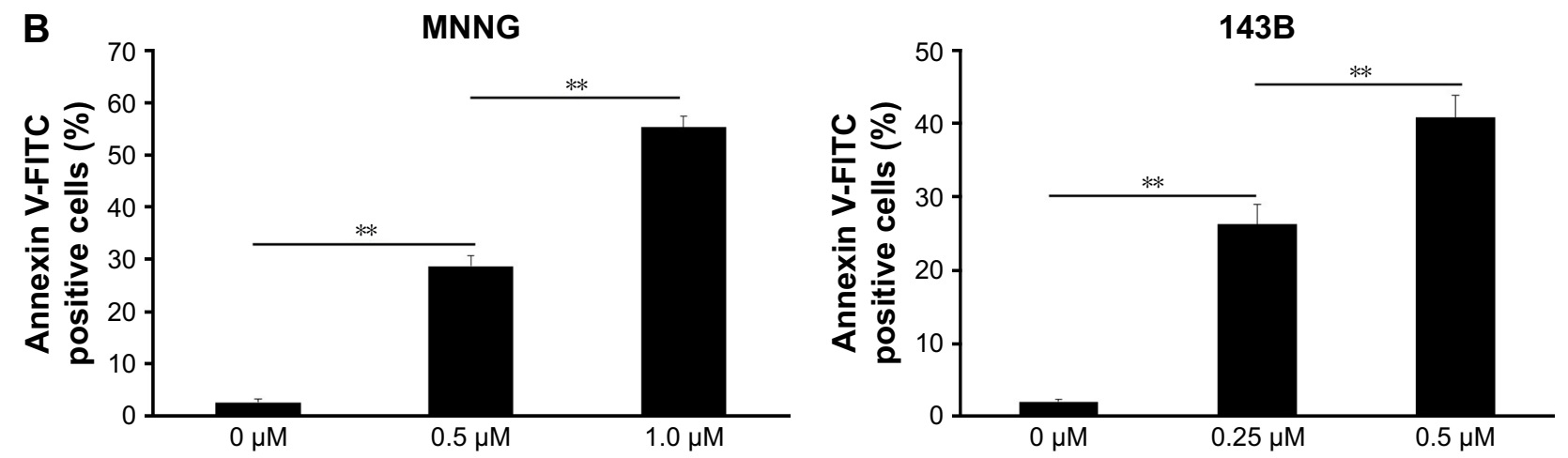

Figure 2 Annexin V-FITC/PI staining of osteosarcoma cells treated with PM.

Notes: (A) MNNG and I43B cells were treated with various doses $(0-I \mu M)$ of PM for $24 \mathrm{~h}$, and apoptosis was determined by flow cytometry followed by Annexin V-FITC/ PI double staining. (B) Annexin V-FITC-stained cells were considered apoptotic and the percentage of apoptotic cells was calculated. Data are expressed as the mean \pm SD $(\mathrm{n}=4) .{ }^{*} \mathrm{p}<0.01$.

\section{PM inhibits protein expression of Akt,} $\mathrm{mTOR}$, and NF-KB in osteosarcoma cells mTOR and NF- $\mathrm{KB}$ are downstream factors of Akt, and Akt activation is involved in the resistance to apoptosis. Therefore, we used Western blot analysis to examine the protein expression levels of Akt, mTOR, NF- $\mathrm{mB}$, and downstream mediators of these signaling molecules (Figure 4). Phosphorylation of Akt and mTOR was inhibited by PM in both osteosarcoma cell lines, whereas total expression levels of Akt and mTOR were unchanged. Moreover, PM reduced the expression of several downstream mediators of Akt, mTOR, and NF- $\kappa$ B. Expression of Bax - proapoptotic effector suppressed by Akt - was elevated by PM treatment.

\section{PM inhibited tumor growth in vivo}

The antitumor effects of PM in vivo were investigated using a xenograft human osteosarcoma model. A concentration of $1 \mathrm{mg} / \mathrm{kg}$ PM applied every other day reduced both tumor volume and tumor weight (Figure 5A and B). The initial administration was set to Day 0 , and administration was done a total of seven times on alternate days. A significant tumor-suppressing effect was observed from Day 8 in MNNG cells and from Day 2 in 143B cells. These results show that PM has antitumor effects in vivo. Liver enzymes, aspartate aminotransferase (AST) and alanine aminotransferase (ALT), were measured as parameters of liver toxicity for both the control and $1 \mathrm{mg} / \mathrm{kg}-\mathrm{PM}$-treated group of nude mice. 
A

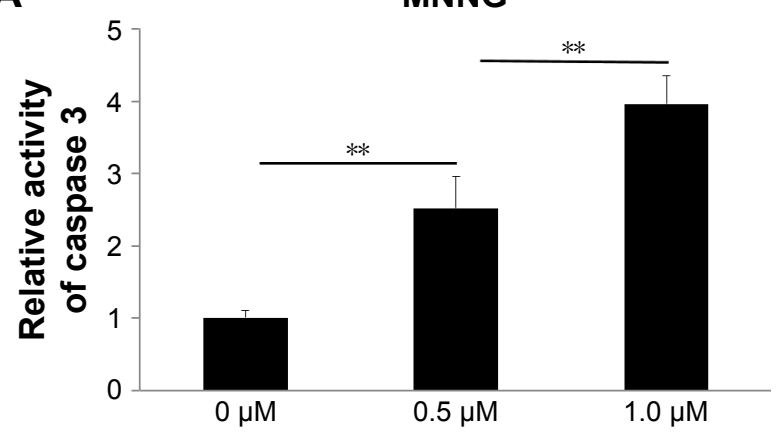

B

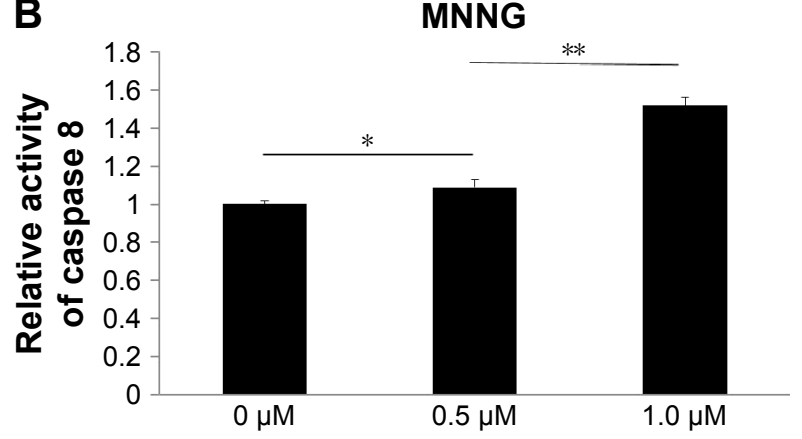

C

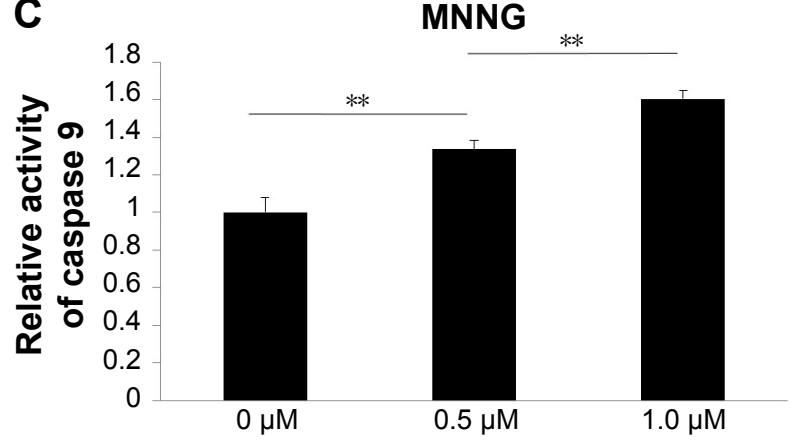

143B

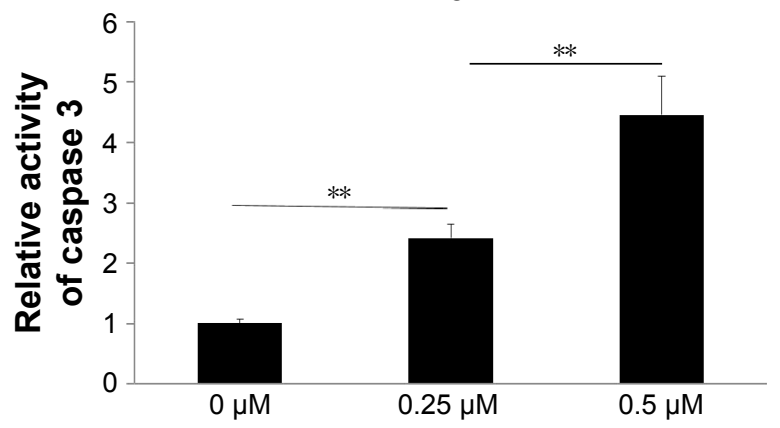

143B

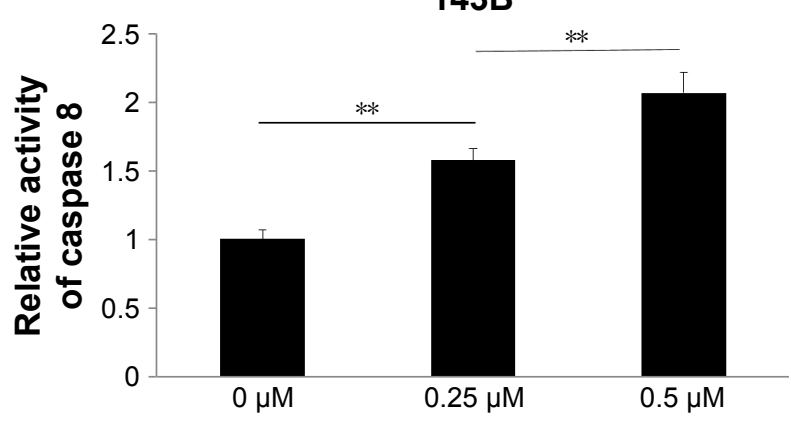

143B

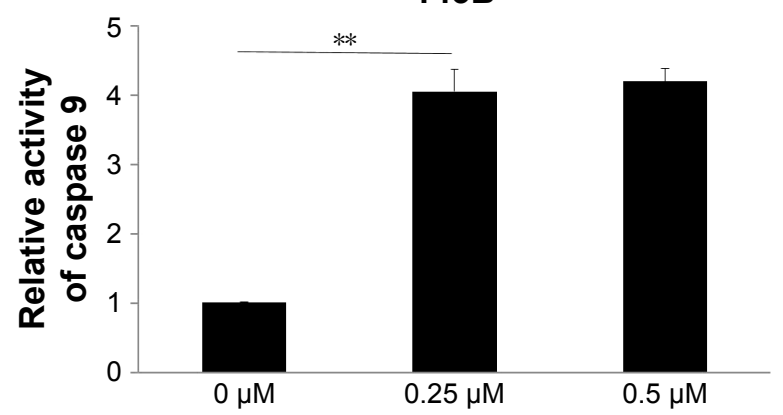

Figure 3 Effects of PM on the activity of caspases 3, 8, and 9 in osteosarcoma cells.

Notes: Caspase activity was measured using a Caspase-Glo assay kit, and the relative ratio is expressed in the bar graph. Caspase 3 activity was measured after I2-h treatment with PM (A); Caspase $8(\mathbf{B})$ and 9 (C) activities were measured after $8 \mathrm{~h}$ of PM treatment. Data are expressed as the mean \pm SD $(n=4)$. ${ }^{p}<0.05$, $* * p<0.0$ I.

As shown in Figure 5C, there were no significant differences in the levels of AST and ALT.

\section{Discussion}

PM is extracted as an active ingredient of traditional medicinal plants, and has anti-inflammatory, antiviral, and antibacterial properties. ${ }^{9,10}$ Recently, there have been reports that PM has antitumor effects against several cancers; ${ }^{11-13}$ however, its effects on osteosarcoma cells have not been elucidated. In this study, we demonstrated for the first time that PM has antitumor effects on human osteosarcoma cells in a time- and dose-dependent manner. Moreover, PM showed tumor growth inhibitory effects in vivo. Wu et al ${ }^{19}$ evaluated the antitumor effects of PM on A-549 (lung), MCF-7 (breast), HepG2, and Hep3B (liver) cells, and reported $\mathrm{IC}_{50}$ values of $0.42-0.61 \mu \mathrm{M}$ at $72 \mathrm{~h}$. In this study, the $\mathrm{IC}_{50}$ value in $\mathrm{MNNG}$ and $143 \mathrm{~B}$ cells was approximately $0.3 \mu \mathrm{M}$ at $72 \mathrm{~h}$. These results suggest that PM has antitumor effects on osteosarcoma, similar to its observed effects in other cancers. Importantly, although PM treatment, at higher concentration, reduced the viability of normal osteoblasts, the effects were not significant compared to PM in osteosarcoma cells.

Cell survival and death are regulated by cell growth and apoptosis signals, and deregulation of either process can lead to cancer. ${ }^{20}$ Thus, the induction of apoptosis is one mechanism by which antitumor drugs can kill cancer cells. ${ }^{21}$ In this study, PM induced apoptosis in a dose-dependent manner, as determined by the Annexin V-PI assay. 


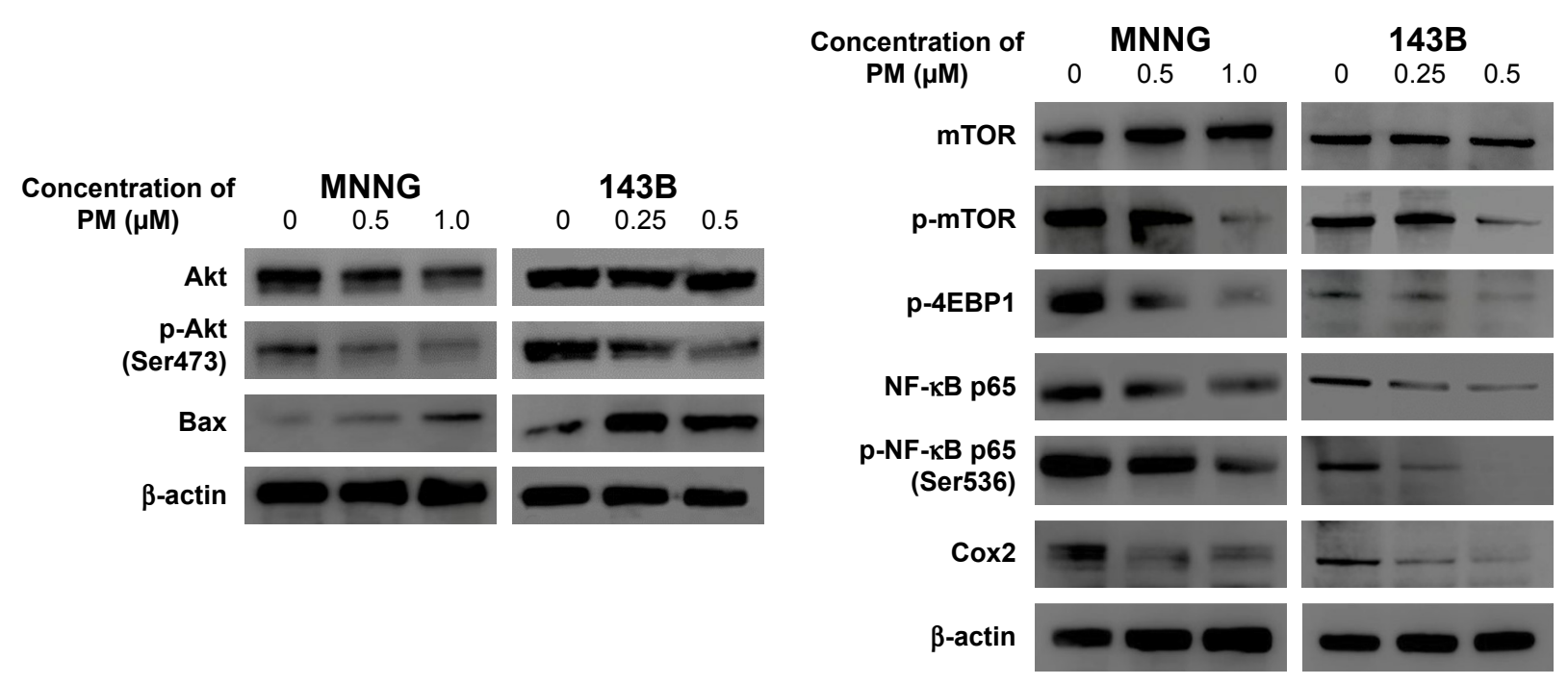

Figure $4 \mathrm{PM}$ inhibits the Akt/mTOR signaling pathway and NF- $\mathrm{KB}$.

Notes: MNNG and I43B cells were treated with PM at concentrations of 0 to $1.0 \mu \mathrm{M}$ for $24 \mathrm{~h}$. Western blot analysis was conducted using antibodies against phospho-

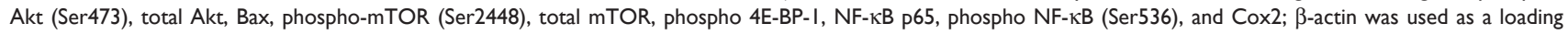
control.

Abbreviation: $\mathrm{p}$, phospho.

Apoptosis is induced as a result of caspase activation..$^{22}$ There are two major caspase cascades: the intrinsic (mitochondrial) pathway that activates caspases 9 and 3 via cytochrome $\mathrm{C}$ release from mitochondria, and the extrinsic (death receptor) pathway that activates caspases 8 and 10 through receptors (so-called "death receptor") present on the cell membrane surface. ${ }^{23}$ In this study, PM induced elevation of caspase 3 and activation of upstream caspases 8 and 9 . These results indicate that apoptosis was induced via both intrinsic and extrinsic pathways.

Activation of the PI3K/Akt/mTOR pathway is one of the drivers of cancer cell growth, and is closely involved in cancer initiation, progression, and treatment resistance. Thus, it is considered an important target in cancer treatment. ${ }^{24}$ Currently, drug development aimed at suppressing PI3K/Akt pathway is progressing, and inhibitors of mTOR are already used in clinical practice. ${ }^{25,26}$ In this study, the expression of phosphorylated Akt and mTOR, indicative of activation, was reduced by PM, suggesting that PM inhibits the growth of osteosarcoma cells by inhibiting the Akt/mTOR pathway.

$\mathrm{NF}-\kappa \mathrm{B}$ is the most important transcription factor involved in inflammation induction, and PM decreased its expression. ${ }^{27,28}$ It was revealed that PM, which has long been used as an anti-inflammatory drug, had anti-inflammatory effects by inhibiting NF- $\mathrm{KB}$, which is not only associated with inflammation but also inhibits apoptosis. ${ }^{29}$ The Akt/mTOR pathway and NF- $\mathrm{\kappa B}$ cross-talk and induce apoptosis. ${ }^{30,31}$ This study revealed that PM induces apoptosis by inhibiting Akt, mTOR, and NF- $\mathrm{kB}$. Moreover, inhibition of Akt $/ \mathrm{mTOR}$ signaling is strongly linked to autophagy and is reported to cross-talk with the apoptotic pathway. ${ }^{32}$ Although a role for PM in the induction of autophagy has not been reported to date, this possibility warrants further investigation in the context of osteosarcoma. Inhibition of the Akt/mTOR pathway and NF- $\mathrm{\kappa B}$ in various cancers enhances the effects of anticancer drugs and radiation and suppresses tumor angiogenesis. ${ }^{33-35}$ Thus, PM has potential as an adjuvant therapy and metastasis inhibitor for osteosarcoma treatment.

The antitumor effects of PM in vivo have been reported for breast cancer, glioma, and colorectal cancer. ${ }^{11,16,36}$ In this study, administration of PM in xenograft mouse models of osteosarcoma resulted in a decrease in tumor volume compared with the untreated group, demonstrating that PM has tumor growth inhibitory effects on osteosarcoma in vivo.

A comprehensive evaluation of PM toxicity is yet to be undertaken. Yousef et $\mathrm{al}^{36}$ reported that no significant change in body weight was observed after treatment of mice with $1 \mathrm{mg} / \mathrm{kg}$ PM every other day, and minimal toxicity has reported in another study. ${ }^{37}$ However, in this work, weight loss of approximately $1.5 \mathrm{~g}$ was observed after administration of the first dose (data not shown), although no obvious liver toxicity was observed as with the result of Wang et al. ${ }^{37}$ PM-associated bone marrow suppression has been reported. ${ }^{38}$ Additional investigation is needed to determine the safest and most effective dosing and administration methods of PM.

In conclusion, PM exhibited antitumor effects on human osteosarcoma cells in vitro and in vivo, and may be a novel therapeutic agent for osteosarcoma. 

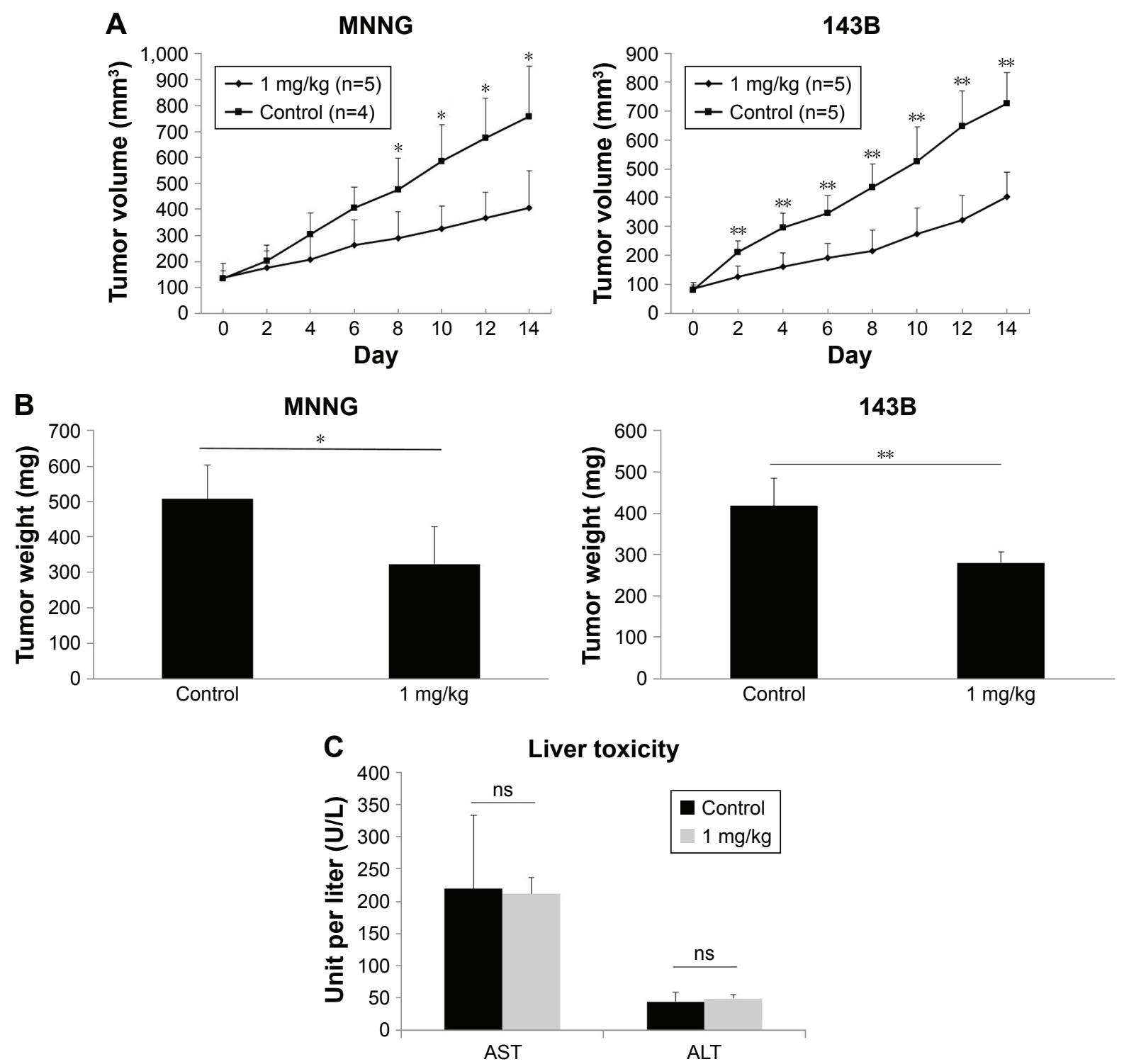

Figure 5 Inhibition of tumor growth by PM in an osteosarcoma xenograft model.

Notes: (A, B) After the tumor volume reached approximately $100 \mathrm{~mm}^{3}$, PM was intraperitoneally administered every other day. $(\mathbf{C})$ Blood samples $(\mathrm{n}=3)$ were collected for liver toxicity assessment. Data are expressed as the mean $\pm S D$. $* p<0.05, * * p<0.01$

Abbreviations: ALT, alanine aminotransferase; AST, aspartate aminotransferase; ns, not significant.

\section{Acknowledgment}

This work was supported by the JSPS KAKENHI (grant nos $17 \mathrm{~K} 10975$ and $15 \mathrm{~K} 10454)$.

\section{Disclosure}

The authors report no conflicts of interest in this work.

\section{References}

1. Damron TA, Ward WG, Stewart A. Osteosarcoma, chondrosarcoma, and Ewing's sarcoma: National Cancer Data Base Report. Clin Orthop Relat Res. 2007;459:40-47.

2. Ferrari S, Palmerini E. Adjuvant and neoadjuvant combination chemotherapy for osteogenic sarcoma. Curr Opin Oncol. 2007;19(4): 341-346.
3. Anderson ME. Update on Survival in Osteosarcoma. Orthop Clin North Am. 2016;47(1):283-292.

4. Ferrari S, Serra M. An update on chemotherapy for osteosarcoma. Expert Opin Pharmacother. 2015;16(18):2727-2736.

5. Ratan R, Patel SR. Chemotherapy for soft tissue sarcoma. Cancer. 2016;122(19):2952-2960.

6. Shaikh AB, Li F, Li M, et al. Present advances and future perspectives of molecular targeted therapy for osteosarcoma. Int J Mol Sci. 2016; 17(4):506.

7. Newman DJ, Cragg GM. Natural products as sources of new drugs from 1981 to 2014. J Nat Prod. 2016;79(3):629-661.

8. De Sanctis R, Marrari A, Santoro A. Trabectedin for the treatment of soft tissue sarcomas. Expert Opin Pharmacother. 2016;17(11): 1569-1577.

9. Akihisa T, Tokuda H, Ichiishi E, et al. Anti-tumor promoting effects of multiflorane-type triterpenoids and cytotoxic activity of karounidiol against human cancer cell lines. Cancer Lett. 2001;173(1):9-14. 
10. Banno N, Akihisa T, Yasukawa K, et al. Anti-inflammatory activities of the triterpene acids from the resin of Boswellia carteri. J Ethnopharmacol. 2006;107(2):249-253.

11. Yan YY, Bai JP, Xie Y, Yu JZ, Ma CG. The triterpenoid pristimerin induces U87 glioma cell apoptosis through reactive oxygen speciesmediated mitochondrial dysfunction. Oncol Lett. 2013;5(1):242-248.

12. Byun JY, Kim MJ, Eum DY, et al. Reactive oxygen species-dependent activation of Bax and poly(ADP-ribose) polymerase- 1 is required for mitochondrial cell death induced by triterpenoid pristimerin in human cervical cancer cells. Mol Pharmacol. 2009;76(4):734-744.

13. Yang H, Landis-Piwowar KR, Lu D, et al. Pristimerin induces apoptosis by targeting the proteasome in prostate cancer cells. J Cell Biochem. 2008;103(1):234-244.

14. Gao X, Liu Y, Deeb D, Arbab AS, Gautam SC. Anticancer activity of pristimerin in ovarian carcinoma cells is mediated through the inhibition of prosurvival Akt/NF-kappaB/mTOR signaling. J Exp Ther Oncol. 2014; 10(4):275-283.

15. Mu X, Shi W, Sun L, Li H, Jiang Z, Zhang L. Pristimerin, a triterpenoid, inhibits tumor angiogenesis by targeting VEGFR2 activation. Molecules. 2012;17(6):6854-6868.

16. Xie $\mathrm{G}, \mathrm{Yu} \mathrm{X}$, Liang $\mathrm{H}$, et al. Pristimerin overcomes adriamycin resistance in breast cancer cells through suppressing Akt signaling. Oncol Lett. 2016;11(5):3111-3116.

17. Ma S, Liu X, Yao Y, et al. Effect of temozolomide on cell viability in gonadotroph adenoma cell lines. Oncol Rep. 2011;26(3):543-550.

18. Mori Y, Terauchi R, Shirai T, et al. Suppression of heat shock protein 70 by siRNA enhances the antitumor effects of cisplatin in cultured human osteosarcoma cells. Cell Stress Chaperones. Epub 2017 May 2.

19. Wu CC, Chan ML, Chen WY, Tsai CY, Chang FR, Wu YC. Pristimerin induces caspase-dependent apoptosis in MDA-MB-231 cells via direct effects on mitochondria. Mol Cancer Ther. 2005;4(8):1277-1285.

20. Hanahan D, Weinberg RA. The hallmarks of cancer. Cell. 2000; 100(1):57-70.

21. Dasari S, Tchounwou PB. Cisplatin in cancer therapy: molecular mechanisms of action. Eur J Pharmacol. 2014;740:364-378.

22. Denault JB, Salvesen GS. Caspases: keys in the ignition of cell death. Chem Rev. 2002;102(12):4489-4500.

23. Wong RS. Apoptosis in cancer: from pathogenesis to treatment. J Exp Clin Cancer Res. 2011;30:87.

24. Polivka J Jr, Janku F. Molecular targets for cancer therapy in the PI3K/ AKT/mTOR pathway. Pharmacol Ther. 2014;142(2):164-175.

25. Liu P, Cheng H, Roberts TM, Zhao JJ. Targeting the phosphoinositide 3-kinase pathway in cancer. Nat Rev Drug Discov. 2009;8(8): $627-644$.
26. Brown JS, Banerji U. Maximising the potential of AKT inhibitors as anti-cancer treatments. Pharmacol Ther. 2017;172:101-115.

27. Brasier AR. The NF-kappaB regulatory network. Cardiovasc Toxicol. 2006;6(2):111-130.

28. Coussens LM, Werb Z. Inflammation and cancer. Nature. 2002; 420(6917):860-867.

29. Karin M. Nuclear factor-kappaB in cancer development and progression. Nature. 2006;441(7092):431-436

30. Hussain AR, Ahmed SO, Ahmed M, et al. Cross-talk between NFkB and the PI3-kinase/AKT pathway can be targeted in primary effusion lymphoma (PEL) cell lines for efficient apoptosis. PLoS One. 2012; 7(6):e39945.

31. Deeb D, Gao X, Liu Y, et al. The inhibition of cell proliferation and induction of apoptosis in pancreatic ductal adenocarcinoma cells by verrucarin $\mathrm{A}$, a macrocyclic trichothecene, is associated with the inhibition of Akt/NF- $\mathrm{B} / \mathrm{mTOR}$ prosurvival signaling. Int J Oncol. 2016;49(3):1139-1147.

32. Eisenberg-Lerner A, Bialik S, Simon HU, Kimchi A. Life and death partners: apoptosis, autophagy and the cross-talk between them. Cell Death Differ. 2009;16(7):966-975.

33. Burris HA 3rd. Overcoming acquired resistance to anticancer therapy: focus on the PI3K/AKT/mTOR pathway. Cancer Chemother Pharmacol. 2013;71(4):829-842.

34. He L, Wu Y, Lin L, et al. Hispidulin, a small flavonoid molecule, suppresses the angiogenesis and growth of human pancreatic cancer by targeting vascular endothelial growth factor receptor 2-mediated PI3K/ Akt/mTOR signaling pathway. Cancer Sci. 2011;102(1):219-225.

35. Tang QL, Xie XB, Wang J, et al. Glycogen synthase kinase-3 $\beta, N F-\kappa B$ signaling, and tumorigenesis of human osteosarcoma. J Natl Cancer Inst. 2012;104(10):749-763.

36. Yousef BA, Hassan HM, Guerram M, et al. Pristimerin inhibits proliferation, migration and invasion, and induces apoptosis in HCT-116 colorectal cancer cells. Biomed Pharmacother. 2016;79:112-119.

37. Wang LN, Wang Y, Lu Y, et al. Pristimerin enhances recombinant adeno-associated virus vector-mediated transgene expression in human cell lines in vitro and murine hepatocytes in vivo. J Integr Med. 2014;12(1):20-34.

38. Lu Z, Jin Y, Chen C, Li J, Cao Q, Pan J. Pristimerin induces apoptosis in imatinib-resistant chronic myelogenous leukemia cells harboring T315I mutation by blocking NF-kappaB signaling and depleting Bcr-Abl. Mol Cancer. 2010;9:112.
OncoTargets and Therapy

\section{Publish your work in this journal}

OncoTargets and Therapy is an international, peer-reviewed, open access journal focusing on the pathological basis of all cancers, potential targets for therapy and treatment protocols employed to improve the management of cancer patients. The journal also focuses on the impact of management programs and new therapeutic agents and protocols on

\section{Dovepress}

patient perspectives such as quality of life, adherence and satisfaction The manuscript management system is completely online and includes a very quick and fair peer-review system, which is all easy to use. Visit http://www.dovepress.com/testimonials.php to read real quotes from published authors. 